Driesenaar, J.A., Smet, P.A.G.M. de, Hulten, R. van, Noordman, J., Dulmen, A.M. van. Cueresponding behaviors during pharmacy counseling sessions with patients with asthma about inhaled corticosteroids: Potential relations with medication beliefs and self-reported adherence. Health Communication: 2016, 31(10), 1266-1275

\begin{tabular}{|l|l|}
\hline $\begin{array}{l}\text { Postprint } \\
\text { Version }\end{array}$ & 1.0 \\
\hline Journal website & $\underline{\text { http://www.tandfonline.com/doi/full/10.1080/10410236.2015.1062g } 7 \mathrm{~h} \text { ive }}$ \\
\hline Pubmed link & $\underline{\text { http://www.ncbi.nlm.nih.gov/pubmed/26940701 }}$ \\
\hline DOI & $10.1080 / 10410236.2015 .1062974$ \\
\hline
\end{tabular}

This is a NIVEL certified Post Print, more info at http://www.nivel.eu

\title{
Cue-responding behaviors during pharmacy counseling sessions with patients with asthma about inhaled corticosteroids: Potential relations with medication beliefs and self-reported adherence
}

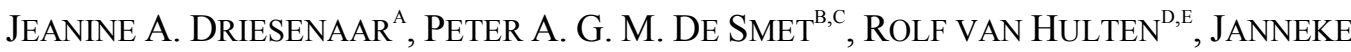 \\ NOORDMAN $^{A}$, AND SANDRA VAN DULMEN ${ }^{A, F, G}$ \\ ${ }^{a}$ NIVEL, Netherlands institute for health services research; \\ ${ }^{b}$ Department of Clinical Pharmacy, Radboud University Medical Center; \\ ${ }^{\mathrm{I}} \mathrm{Q} \mathrm{H}$ Healthcare, Radboud University Medical Center; \\ dDivision of Pharmacoepidemiology and Clinical Pharmacology, Utrecht University; \\ ${ }^{\mathrm{e}}$ Department of Pharmacotherapy and Pharmaceutical Care, University of Groningen; \\ fDepartment of Primary and Community Care, Radboud University Medical Center; \\ ${ }^{g}$ Faculty of Health Sciences, Buskerud and Vestfold University College
}

\begin{abstract}
The aim of this study was to examine cue-responding behavior at the pharmacy while counseling about inhaled corticosteroids (ICS) in relation to medication adherence and medication beliefs. Patients with asthma aged $\geq 18$ years using ICS were recruited from 12 pharmacies. Counseling sessions were videorecorded.

Patients' emotional and informational cues and pharmacists' and pharmacy technicians' cueresponding behaviors were coded using an expanded version of the Medical Interview Aural Rating Scale. The Beliefs about Medicines Questionnaire assessed patients' ICS concern and necessity beliefs.

Self-reported ICS adherence was measured by four questions. During the 86 sessions, patients expressed on average 2.3, mostly informational, cues (70.8\%). In $26.7 \%$ of the sessions, no cues were expressed.

Pharmacists' and technicians' responses to emotional cues (59.3\%) were mostly inadequate, and to informational cues mostly appropriate (63.6\%). Providing inappropriate information $(20.3 \%)$ was related to higher concerns post session $(p<.05)$, and cue exploration to higher self-reported adherence at 3 months ( $p$ $<.05)$. Apparently, providers' responses to patients' cues might have therapeutic value. In addition, patients might need to be encouraged to ask questions and express their concerns.
\end{abstract}


Driesenaar, J.A., Smet, P.A.G.M. de, Hulten, R. van, Noordman, J., Dulmen, A.M. van. Cueresponding behaviors during pharmacy counseling sessions with patients with asthma about inhaled corticosteroids: Potential relations with medication beliefs and self-reported adherence. Health Communication: 2016, 31(10), 1266-1275

\section{BACKGROUND}

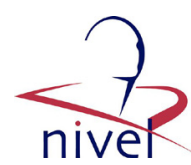

Asthma is a growing health burden. Approximately 300 million people suffer from asthma worldwide, with mortality rates of 250,000 deaths per year (World Health Organization, 2007). Inhaled corticosteroids (ICS) are frequently used in the management of asthma and have to be taken on a long-term and regular basis (Global Initiative for Asthma, 2013). However, about $40 \%$ of asthma patients do not take ICS as prescribed (Sabate, 2003). This suboptimal adherence leads to poor asthma control, increased risk of asthma events, and high health care costs (Murphy et al., 2012; Sabate, 2003).

Patients' insufficient knowledge, misconceptions, and beliefs about ICS are related to suboptimal adherence (Al- Jahdali et al., 2007; Choi, Westermann, Sayles, Mancuso, \& Charlson, 2008; Horne, 2006; Horne \& Weinman, 1999a).

Some patients think that ICS are ineffective (Choi et al., 2008); others only use ICS when experiencing symptoms, rather than regularly (Baan \& Heijmans, 2011). Horne et al.

examined patients' ICS beliefs in relation to medication adherence (Horne \& Weinman, 1999b). They distinguished two kinds of beliefs, namely, concern and necessity beliefs.

Concern beliefs refer to worries about, for instance, side effects and drug dependency. Necessity beliefs refer to the conviction that medication is needed for maintaining health.

Higher concerns and lower necessity beliefs have shown to be associated with lower adherence. Many patients report having concerns about using ICS, especially about potential addiction to ICS and side effects, like reduced bone density, weight gain, and unknown long-term effects (Al-Jahdali et al., 2007; Boulet, 1998; Choi et al., 2008; Horne, 2006).

To improve ICS adherence, health care providers have to assist patients to increase their knowledge, change their misconceptions, and diminish their concerns about ICS. They should attend to patients' needs and respond to these in an adequate or supportive way (Epstein et al., 2005). Several studies found a positive association between such patient-centered communication and medication adherence, but the results are, as yet, inconclusive (Mead \& Bower, 2002; Michie, Miles, \& Weinman, 2003).

According to Engel's biopsychosocial model, patients have "a need to know and to understand" and "a need to feel known and understood" (Bensing \& Dronkers, 1992; Engel, 1977). The first refers to informational needs about medical issues. The second denotes that patients have emotional needs, such as a need for support, acceptance, and respect.

Bensing and colleagues (Bensing \& Verhaak, 2004) transformed Engels' model into the "stress-coping model" that indicates that health care providers have to take these two different needs into account, and that each need requires another approach or response from the health care provider.

To fulfill patients' informational needs, the exchange of appropriate medical information about the treatment, illness, and medication is important. This type of exchange is called "instrumental communication." To meet patients' emotional needs, attention has to be paid to patients' feelings, concerns, and psychosocial issues. Such 
Driesenaar, J.A., Smet, P.A.G.M. de, Hulten, R. van, Noordman, J., Dulmen, A.M. van. Cueresponding behaviors during pharmacy counseling sessions with patients with asthma about inhaled corticosteroids: Potential relations with medication beliefs and self-reported adherence. Health Communication: 2016, 31(10), 1266-1275

"affective communication" includes behaviors such as listening to patients' concerns, showing empathy, and reassuring patients (Bensing \& Dronkers, 1992). Instrumental and affective communication are expected to enhance a patient's problem-orientedivel and emotional coping behaviors, respectively.

A prerequisite for such communication is that patients voice their needs clearly. However, many patients only give implicit "cues" (Zimmermann, Del Piccolo, \& Finset, 2007). Many patients with asthma do not discuss their worries about ICS with their health care provider or mention less than one psychosocial concern about ICS during counseling sessions at the pharmacy (Boulet, 1998; Driesenaar, De Smet, Van Hulten, Hu, \& Van Dulmen, 2016). Clearly, there is a need for health care providers to identify and explore implicitly expressed cues (Zimmermann et al., 2007) and, in line with the stress-coping model, to respond to these in an appropriate way. The present study focuses on the community pharmacy.

Since the emphasis of pharmacists' role has shifted from a logistic dispensing role to a more patient-centered guiding role, pharmacists are more engaged in patient education and counseling (Blom \& Krass, 2011). In the Netherlands, many pharmacies annually conduct counseling sessions to monitor patients' chronic medication use, but these are not yet common practice everywhere (Van Mil, 2005). So far, there is a lack of knowledge of the way patients with asthma express their informational and emotional needs and how pharmacists respond to them during counseling sessions.

In this study, we focus especially on cues as an expression of patients' needs. Differences may exist between pharmacists and pharmacy technicians in their cueresponding behaviors and patients' expressions of cues during these sessions, as shown in other research about instrumental and affective communication (Driesenaar et al., 2016).

Therefore, the aims of this study are (1) to examine asthmatic patients' informational and emotional cues during counseling sessions about ICS and their relationship with medication beliefs and self-reported adherence, (2) to investigate pharmacists' and pharmacy technicians' cue-responding behaviors and their relationship with these outcomes, and (3) to explore the differences in expressions of cues and responses between pharmacists and pharmacy technicians.

\section{METHOD}

\section{Setting}

This observational study is part of a larger project investigating the communication of community pharmacists and pharmacy technicians with patients with asthma and chronic obstructive pulmonary disease (COPD) about their ICS use.

The research proposal was assessed by the Medical Ethics Committee (METC) of the University Medical Centre Utrecht (UMCU). The METC concluded that this study did not fall within the remit of the Law on Medical Scientific Research involving Human Beings.

In total, 130 community pharmacies were invited by the Utrecht Pharmacy Practice Network for Education and Research (UPPER) to join the study, of which 12 community pharmacies were willing to participate. At each participating pharmacy, one pharmacist and one pharmacy technician had several counseling sessions with 
Driesenaar, J.A., Smet, P.A.G.M. de, Hulten, R. van, Noordman, J., Dulmen, A.M. van. Cueresponding behaviors during pharmacy counseling sessions with patients with asthma about inhaled corticosteroids: Potential relations with medication beliefs and self-reported adherence. Health Communication: 2016, 31(10), 1266-1275

patients, depending on the number of participating patients of the particular pharmacy, and on an agreed maximum number of participants per pharmacy. The purpose of a counseling session was to talk individually with a patient about hije or her medication use. Several issues could be discussed, like inhalation technique, ICS dose, reason for use, adherence to ICS, the degree of asthma control, and so on. To get as the best possible authentic impression of providers' communication styles, only general instructions were provided about the counseling sessions, that is, "discuss patients' experiences with ICS use, the effectiveness and (possible) sideeffects of ICS, and whether the patient uses ICS in an appropriate way." Pharmacists and pharmacy technicians were unaware of the specific aims of the study.

\section{Participants}

Patients were recruited from the participating pharmacies and were eligible for the study when they were 18 years of age or older, were diagnosed with asthma or COPD (based on selfreport), had been using ICS for at least 1 year, and had filled two or more ICS prescriptions in the preceding year. Patients living in an institution were excluded. For the purpose of this study, only data of patients with self-reported asthma (symptoms) were used.

\section{Procedure}

In total, 1,952 potentially eligible patients received an information package from their pharmacists, with an invitational letter, a questionnaire, and an informed consent form, by post. This baseline questionnaire assessed, among other things, patients' sociodemographic characteristics and asthma control (Asthma Control Questionnaire) (Juniper, O’Byrne, Guyatt, Ferrie, \& King, 1999; Sastre et al., 2010). To participate in the study, patients had to return the completed baseline questionnaire and a signed informed consent form. To protect patients' privacy, these had to be returned separately.

Participants were randomly allocated to the intervention group, which received a planned counseling session, or the control group, without a planned counseling visit. In this study, we only consider the data of patients with asthma who had a counseling session. Within 2 months after inclusion, participants had one planned counseling session in the consulting room at the pharmacy. These sessions were videotaped using an unmanned camera, directed at the pharmacist or pharmacy technician. Patients filled in a questionnaire directly after the counseling session. Three months after baseline, participants again received a questionnaire by post.

\section{Measurements}

An expanded version of the Medical Interview Aural Rating Scale (MIARS) was used to analyze the video recordings and to identify the number of patients' emotional cues and how pharmacists and pharmacy technicians responded to emotional cues (Heaven, Clegg, \& Maguire, 2006; Heaven \& Green, 2001). The coding scheme was expanded to capture also informational cues and responses to these (Jansen et al., 2010; Noordman \& van Dulmen, 2013). This version of the MIARS corresponds with the elements of the stress-coping model and enables measurement of the two types of patient- provider communication (i.e., detecting patients' emotional and informational cues and the subsequent affective or instrumental response provided by the pharmacist or pharmacy technician). 
Driesenaar, J.A., Smet, P.A.G.M. de, Hulten, R. van, Noordman, J., Dulmen, A.M. van. Cueresponding behaviors during pharmacy counseling sessions with patients with asthma about inhaled corticosteroids: Potential relations with medication beliefs and self-reported adherence. Health Communication: 2016, 31(10), 1266-1275

A cue is defined as a verbal or nonverbal hint or expression (word or sentence) of a patient that indicates that the issue is important to the patient or that the issue woutd 7 need clarification from a health care provider, or that indicates a need for nivel information, or a worry or concern.

"Turns" were used as units of observation and analysis.

A turn is the period a patient, pharmacist, or pharmacy technician is talking before the next speaker takes over. Responses of a pharmacist and pharmacy technician were coded in the first turn after the patient's cue (i.e., lag 1).

Observers coded the cues and responses directly from the videotapes with Observer XT7 software (Noldus, Trienes, Hendriksen, Jansen, \& Jansen, 2000), which enables observation of verbal as well as nonverbal aspects, like emotional tone of voice. Each recording was coded by one observer. The times of cues and responses were registered in order to provide sequential data.

\section{Emotional cues and responses}

The MIARS distinguishes three levels of emotional cues, based on their degree of intensity: (1) hints of worry or concern, (2) mention of worry or concern, and (3) clear expression of worry or concern. These cues can be followed by one of these types of responses: (1) exploration (by eliciting, clarification, or educated guess), (2) acknowledgment (by an emphatic statement, reflection, checking, or minimal encouragement [i.e., backchannel responses, as "mmmh" and "aha," and agreements, as "right" and "okay"]), (3) factual clarification (by giving/questioning about clinical relevant information, without responding to the emotion), (4) distancing (by switching focus or giving premature reassurance or inappropriate advice), or (5) overt blocking (Table 1). According to the MIARS, exploration and acknowledgment are considered adequate responses to emotional cues, whereas factual clarification, distancing, and overt blocking are inadequate responses.

\section{Informational cues and responses}

Informational cues are questions or indirect statements indicating that the patient is seeking information. An example is "I do not know if I use the inhaler correctly." In addition, patients' questions in order to gather extra information or explanation were also coded as informational cues (e.g., "Why?" and "What do you mean?"). There are four informational categories: (1) medical information about ICS and inhaler use, (2) other medical information, (3) practical information, and (4) information about lifestyle. Responses to informational cues are to some extent comparable to the emotional responses: (1) exploration, (2) giving appropriate information, (3) giving inappropriate information (i.e., incorrect, incomplete, or ambiguous information), (4) referral (by addressing to come back to it at a later moment in the visit), (5) distancing, and (6) overt blocking (Table 1).

\section{Interrater reliability}

Two coders were trained in using the MIARS. The main coder coded all observations $(n=86)$. A second observer coded a random $10 \%(n=9)$ of the main coders' observations.

Reliability was determined for all cues and responses using the intraclass correlation coefficient (ICC). ICC reliability was good and ranged from 0.98 to 1.00 for both emotional and informational cues and responses (Bruton, Conway, \& Holgate, 2000). 
Driesenaar, J.A., Smet, P.A.G.M. de, Hulten, R. van, Noordman, J., Dulmen, A.M. van. Cueresponding behaviors during pharmacy counseling sessions with patients with asthma about inhaled corticosteroids: Potential relations with medication beliefs and self-reported adherence. Health Communication: 2016, 31(10), 1266-1275

Medication adherence and medication beliefs baseline. Adherence was assessed by a selfreported questionnaire comprising four dichotomous items comparable to the items from the Morisky Medication Adherence Scale (Morisky, Green, \& Levine, 1986). An example is "Do you ever forgot to take your medicine?" Each question can be answered with yes ( 0 points) or no ( 1 point). Scores were added up to generate a score between 0 and 4 . A score closer to 4 indicates higher adherence. Only completed scales were analyzed (baseline $n=86$; at 3 months $n=79$ ).

ICS beliefs were measured at three moments: at baseline, directly after the counseling session, and at 3 months after baseline. The Beliefs about Medicines Questionnaire (BMQspecific) assessed beliefs about ICS, containing a necessity scale and a concerns scale (Horne, Weinman, \& Hankins, 1999). An example of a necessity item is "Without these medicines, I would be very ill." An example of a concerns item is "I sometimes worry about long-term effects of these medicines." Each scale consists of five 5-point Likert scale items, ranging from strongly disagree to strongly agree. The scores were added up for each scale to produce a score ranging between 5 and 25. A maximum of one missing per case per scale was allowed; then, the scale score was determined on the mean score of four items, multiplied by 5 . Higher scores indicate stronger beliefs.

\section{[TABLE 1]}

\section{Statistical analysis}

Sequence analysis was performed on the sequential data by using descriptive statistics and scoring manually which response followed each cue, resulting in cross tables. To determine whether the number of cues and responses differed between pharmacists' sessions and those of pharmacy technicians, two-sample proportions tests were carried out on each cue and response.

To control for the clustering of patients in pharmacies, multilevel regression analysis was used to examine the relationships between cues and responses and patient outcomes in terms of medication beliefs after the counseling session and at follow-up 3 months after baseline, and self-reported adherence at follow-up 3 months after baseline. Difference scores were calculated for each patient outcome measure (i.e., score at follow-up minus score at baseline). Because of low numbers of cues and responses per session, all independent variables (i.e., all types of cues and responses) were dichotomized according to whether a particular cue/response "did not occur" or "did occur" ( 0 vs. $\geq 1$ ) during a session. Only independent variables were analyzed when they occurred in at least 10 sessions. This is decided in view of generalizability of the results, which have to be based on an adequate amount of cases (one session is one case in the analysis). Separate multilevel linear regression analyses were performed on (1) emotional cues (level 1 hints), (2) informational cues (medical ICS/inhaler use, medical other, and practical), (3) responses to emotional cues (acknowledgment and factual clarification) and (4) responses to informational cues (exploration, appropriate and inappropriate information), in relation to the difference scores of the patient outcomes measures. Multilevel analyses were done using MLwiN 2.25. Descriptive statistics were calculated using Stata 12.1. 
Driesenaar, J.A., Smet, P.A.G.M. de, Hulten, R. van, Noordman, J., Dulmen, A.M. van. Cueresponding behaviors during pharmacy counseling sessions with patients with asthma about inhaled corticosteroids: Potential relations with medication beliefs and self-reported adherence. Health Communication: 2016, 31(10), 1266-1275

\section{RESULTS}

\section{Study sample}

Of 429 patients who responded, 199 patients were allocated to the intervention group and were invited for a counseling session. Of these, 30 patients dropped out (15.1\%). Reasons for drop-out were: not reachable by phone/e-mail, involuntary withdrawal (e.g., due to health condition), no longer using ICS, recently had a session about ICS or asthma, and do not want to participate anymore. Of the 169 patients who had a session, 86 patients reported to have asthma (symptoms). The majority of these asthma patients were female $(67.4 \%)$. The mean age was 58.3 years $(\mathrm{SD}=15.0)$ (Table 2).

All 86 patients with asthma filled in the questionnaire after the session, but one did not complete the BMQ. At 3 months after baseline 81 patients returned the follow-up questionnaire, of which 79 patients completed the BMQ and adherence scale completely for analysis.

\section{[TABLE 2]}

Half of the pharmacists were male; all pharmacy technicians were female. Mean age of pharmacists was 36.7 years $(\mathrm{SD}=11.5)$, and mean age for pharmacy technicians was 35.4 years $(\mathrm{SD}=11.9)$ (Table 2$)$. Pharmacists performed on average 3.7 counseling sessions (range 1-7 sessions) and pharmacy technicians 3.5 sessions (range 1-7 sessions).

\section{Frequencies of patients' cues and pharmacists' and pharmacy technicians' responses}

In 63 of the 86 counseling sessions (73.3\%), patients expressed cues. Of these, 37 sessions $(58.7 \%)$ were with a pharmacist and 26 sessions $(41.3 \%)$ with a pharmacy technician. Results based on all 86 cases show that patients gave on average 0.7 emotional cues (median $=0$, range: $0-5$ ) and 1.7 informational cues (median $=2$, range: $0-11$ ) per session, resulting in a mean of 2.3 cues (median $=2$, range: $0-13$ ) per session. Specified by type of cue, only 31 patients $(36.1 \%)$ expressed emotional cues, and informational cues were expressed by 55 patients $(64.0 \%)$. In sessions with emotional cues, on average 1.9 emotional cues were expressed $($ median $=2)$, and in sessions with informational cues, patients gave on average 2.6 informational cues (median $=2$ ). Mean session length was 13.8 minutes $(\mathrm{SD}=6.3$ ) (data not shown). Patients more often expressed informational cues than emotional cues $(70.8 \%$ versus $29.2 \%)$ (Table 3$)$. Most cues were related to ICS and inhaler use $(65.0 \%$ of informational cues). The majority of emotional cues were hints (93.2\% of emotional cues). Patients gave no clear emotional expressions (level 3 cues) and no cues about lifestyle issues.

Two-sample proportion tests revealed that pharmacists' sessions did not differ significantly from pharmacy technicians' sessions in the number of cues and responses. Both provider types most often responded to emotional cues with a factual clarification (49.2\%) or acknowledgment (35.6\%).

Exploration and overt blocking occurred least frequently as a response to an emotional cue (both 5.9\%). The responses to emotional cues were adequate in $40.7 \%$ of the responses $(5.1 \%+35.6 \%)$. To informational cues, pharmacists and pharmacy technicians most frequently provided appropriate information $(63.6 \%)$, followed by inappropriate information (20.3\%) and an exploration of the cue (12.6\%). 
Driesenaar, J.A., Smet, P.A.G.M. de, Hulten, R. van, Noordman, J., Dulmen, A.M. van. Cueresponding behaviors during pharmacy counseling sessions with patients with asthma about inhaled corticosteroids: Potential relations with medication beliefs and self-reported adherence. Health Communication: 2016, 31(10), 1266-1275

\section{Communication sequences between patients and pharmacists and pharmacy \\ technicians
The sequence analysis depicted in Table 4 shows that pharmacists and pharmacynive technicians most often responded with a factual clarification to patients' emotional cues (level 1 and 2), and with acknowledgment of emotional hints (level 1). Clear emotional expressions (level 2) were only followed by factual clarifications $(75.0 \%)$ or an exploration of the cue $(25.0 \%)$. Informational cues were most frequently followed by appropriate information. When pharmacists or technicians gave an inappropriate information response to an informational cue, this was most of the time to an informational cue related to medical ICS/inhaler issues. Referring and distancing were only a response to cues related to the "medical other" category.}

\section{[TABLE 3][TABLE4]}

\section{Relationship between cues, responses, and medication beliefs and adherence}

No relationships were found between the expression of (emotional and informational) cues on the one hand, and patients' medication beliefs and adherence on the other (Table 5). A significant relationship was found between responding with inappropriate information to informational cues, and concerns after the session $(\beta=$ $1.57, \mathrm{p}<.05$ ); a positive difference score on the concerns scale indicates that concerns were higher after the visit when inappropriate information had been given to informational cues, compared to no inappropriate information as response. In addition, a significant association was found between exploration on informational cues and self-reported adherence 3 months after baseline (i.e., approximately 1 month after the session $)(\beta=0.55, \mathrm{p}<.05)$; here a positive difference score on the self-reported scale indicates that exploration of informational cues was positively related to adherence, compared to no exploration.

\section{[TABLE 5]}

\section{DISCUSSION}

In line with other research about patients' cues, we found that patients with asthma expressed few cues during planned counseling sessions at the pharmacy (Zimmermann et al., 2007) and more than one-fourth expressed no cues at all. The reason for this can be threefold. First, patients might have few concerns or not much need for information. The majority of patients in this study used ICS for longer than 5 years, which could implicate that they have sufficient knowledge about ICS and asthma, or perceive that they have this.

Second, they might not have experienced the opportunity to express themselves. Third, patients might not have wanted or dared to express their needs. This reticence could be explained by findings that patients do not yet perceive pharmacists as a health care provider who counsels them in their medication needs and concerns (Law, Ray, Knapp, \& Balesh, 2003; Worley et al., 2007). Further research is needed to determine whether patients will be more open in their communication toward pharmacists and pharmacy technicians in the future.

[table 5] When patients did express emotional cues, these cues were most of the time expressed as "hints," which are, by definition, difficult to detect because of their implicit character. No clear expressions of cues took place. Pharmacists and 
Driesenaar, J.A., Smet, P.A.G.M. de, Hulten, R. van, Noordman, J., Dulmen, A.M. van. Cueresponding behaviors during pharmacy counseling sessions with patients with asthma about inhaled corticosteroids: Potential relations with medication beliefs and self-reported adherence. Health Communication: 2016, 31(10), 1266-1275

pharmacy technicians most often responded to an emotional cue with a factual clarification, without further exploration of the question behind the implicit cue. About $60 \%$ of the responses to emotional cues were inadequate, which means that ivel there is room for improvement in the detection and handling of emotional cues. Previous research already indicated that pharmacists' communication is more medication oriented than patientcentered; the communication is often more focused on the (bio)medical aspects of the drug use than on affective and psychosocial issues (Chong, Aslani, \& Chen, 2013; Greenhill, Anderson, Avery, \& Pilnick, 2011; Murad, Chatterley, \& Guirguis, 2013). This could explain our finding that pharmacists and pharmacy technicians most often responded with factual clarification to emotional cues. Still, more than one out of three emotional cues was acknowledged, by showing empathy, reflecting, checking, or giving minimal encouragement. This indicates that these professionals possess the skills to handle the patients' concerns adequately to some extent, and that they need to be trained to improve their skills.

In line with the MIARS, a factual clarification was categorized as an inadequate response. It can be argued that a factual clarification is not as inadequate as distancing and overt blocking. This might be taken into account in future research. In this study, we decided to follow the initial categorization, because when responding with a factual clarification the patient's emotion is ignored and therefore the response is not considered to be adequate.

Our findings are difficult to compare directly with other cue-responding studies, because of dissimilarities in settings (e.g., hospital), health care providers (e.g., physician or nurse), and definitions and operationalization of cues and responses (Zimmermann et al., 2007). In addition, many studies that also used the MIARS were performed among cancer patients (Jansen et al., 2010; Uitterhoeve et al., 2009, 2008). Taking this into account, other studies show comparable findings, in that health care providers "missed" $53-72 \%$ of emotional cues in consultations with patients, by inadequately responding to them (Zimmermann et al., 2007). Studies that did use the MIARS were among nurses, and showed that $50-60.6 \%$ of their responses were inadequate (Jansen et al., 2010; Uitterhoeve et al., 2009, 2008). Our study confirms these findings, which underline the importance of improving health care providers' affective behavior, that is, becoming more responsive to patients' concerns. In contrast to this, a study about consultations of pharmacist prescribers in England found that $81 \%$ of responses to emotional cues and concerns were adequate (Riley et al., 2013). Emotional cues, concerns, and responses were measured using another method but comparable to the MIARS. These opposite findings can be due to different goals of the sessions (prescribing vs. only counseling), other patient groups (patients with acute and chronic conditions vs. only chronic asthmatic patients), or pharmacists' experiences in communication and counseling. Informational cues expressed by patients were merely related to ICS and inhaler use, which was the main aim of the session and therefore explicable. No informational cues were expressed about lifestyle. Pharmacist and pharmacy technicians responded most often in an adequate way to informational cues by giving appropriate information. By doing this, they fulfilled patients' needs for information. However, in one out of five informational cue responses, inappropriate information was given. Providing wrong or incomplete information to patients could lead to incorrect knowledge, which could subsequently lead to nonadherence. We found that the 
Driesenaar, J.A., Smet, P.A.G.M. de, Hulten, R. van, Noordman, J., Dulmen, A.M. van. Cueresponding behaviors during pharmacy counseling sessions with patients with asthma about inhaled corticosteroids: Potential relations with medication beliefs and self-reported adherence. Health Communication: 2016, 31(10), 1266-1275

provision of inappropriate information by pharmacists and pharmacy technicians during the sessions was significantly related to more concerns about ICS after the session. This suggests that inappropriate information made patients more worried about using ICS. The information could have been worrisome or confusing, or could just not have fulfilled patients' needs sufficiently.

Moreover, exploration of informational cues was associated with higher adherence at 3 months (i.e., about 1 month after the session). By exploring an informational cue, health care providers examine what underlies the patient's request for information and may subsequently be able to more adequately fulfill the patient's informational need. The resulting increase in knowledge could explain the positive association with medication adherence, as knowledge is known to be one of the determinants of adherence. The association we found can also be explained by the mediating role of self-efficacy (i.e., an individual's confidence in his or her ability to take medication as prescribed) (Unni \& Farris, 2011).

The relationships found in this study are in conformity with the stress-coping perspective and support the assumption that appropriate instrumental communication contributes to patients' health (by improved medication adherence), whereas inappropriate instrumental communication does not. We even found a negative effect of providing inappropriate information (i.e., an increase of patients' concerns). According to the stress-coping model, instrumental communication intervenes on patients' problem-oriented coping skills. Further research is needed to explain and interpret our findings in light of problem-solving coping. Furthermore, our findings suggest that the type of response to informational cues is important in relation to concern beliefs and medication adherence, whereas patients' expression of cues and concerns and providers' responses to emotional cues are not. This is not entirely in line with assumptions that could be drawn from the stresscoping model and patient-centered communication that emphasize the attention to patients' emotions and the importance of affective communication. This could indicate that affective communication has no effect on medication beliefs and adherence, but does not imply that affective communication is not important itself. Other outcomes measures might be more relevant in relation to affective communication, such as patient satisfaction, quality of life, and perceived quality of care. Our findings are also in contrast with the research previously performed on the relationships between types of cues, responses, and other patient outcomes. Only a few studies looked at these relationships. For instance, some examined the relationship between emotional cues, responses, and patient satisfaction. Although one study found no associations (Butow, Brown, Cogar, Tattersall, \& Dunn, 2002), Bertakis et al. found that expressions of emotional cues (i.e., "psychosocial topics") were related to patient satisfaction (Bertakis, Roter, \& Putnam, 1991), whereas the study of Uitterhoeve et al. indicated an association between the expression of emotional cues as well as adequate cue-response behavior and patient satisfaction (Uitterhoeve et al., 2009). In addition, Jansen et al. found only (marginally) significant relations between two types of responses to emotional cues and patient recall. Expressions of (emotional and informational) cues and responses to informational cues were not related to patient recall.

As stated before, these divergent findings might be due to dissimilarities of study settings, type of health care provider, patient groups, and outcome measures. Further 
Driesenaar, J.A., Smet, P.A.G.M. de, Hulten, R. van, Noordman, J., Dulmen, A.M. van. Cueresponding behaviors during pharmacy counseling sessions with patients with asthma about inhaled corticosteroids: Potential relations with medication beliefs and self-reported adherence. Health Communication: 2016, 31(10), 1266-1275

research is needed to investigate more extensively the relation between emotional and informational cues and responses, on the one hand, and patient outcomes on the 7 other hand. This applies to the pharmacy profession, as well as to other health carivel professions.

Contrary to previous findings about the content and process of counseling sessions at the pharmacy, no differences between pharmacists' and pharmacy technicians' sessions have been found regarding the number of cues and responses (Driesenaar et al., 2016).

Finally, there are some directions for future research. First, in this study, the coded response was based on the first lag after the patient's cue. In future studies, other lags might also be taken into account to study the communication and the relations with patient outcomes. Second, more insight is needed into the stress-coping model. A closer look can be taken on different elements of instrumental and affective communication in relation to coping and patient (health) outcomes. Attention needs to be paid to cue-responding behaviors, as well as to more general patient-provider communication.

At last, interventions can be developed and tested to improve health care providers' skills to detect patients' cues and respond to them adequately.

\section{Strengths and limitations}

To our knowledge, no previous research has explored patients' cues and pharmacists' and pharmacy technicians' cue-responding behavior during counseling sessions, or the relationship between cues, responses, and patient outcomes in terms of medication beliefs and self-reported adherence.

This study has some limitations. First, our findings are only based on the sessions in which cues and responses were expressed. However, in more than one-fourth of the sessions no cues were expressed. This implies that our findings are not readily generalizable, but only give insight into sessions in which cues and responses did occur. Second, selection bias might have occurred during pharmacy as well as patient recruitment.

The health care providers in our study might have shown better cue-responding behavior than nonparticipants would have shown, whereas participating patients might have more informational needs or concerns than nonparticipants. This hampers the generalizability of our findings. However, when looking at the level of patients' concerns at baseline, it is found that these are low (below midscale of 13). Because of the small number of expressed cues and responses, we were not able to examine all types of cues and responses in relation to patient outcomes, nor could we control for confounders. In addition, we performed many statistical tests. Therefore, we should be cautious attaching clinical meaning to the associations we found.

Replication of this study is recommended.

Furthermore, we are aware of the fact that after the MIARS had been developed, a new system called VR-CoDES is now endorsed in the field of communication studies (Del Piccolo, Finset, \& Zimmermann, 2009). However, since our previous study about the content of counseling sessions at the pharmacy revealed that these sessions are for a great part instrumental (Driesenaar et al., 2016), we decided to use the expanded MIARS that has a part to measure this as well. Finally, we only used a self-reported measure of adherence. Using a more objective measure, for instance, pharmacy refill records, was difficult, because ICS prescriptions are only given quarterly, and refill adherence has to be determined with multiple prescriptions per 
Driesenaar, J.A., Smet, P.A.G.M. de, Hulten, R. van, Noordman, J., Dulmen, A.M. van. Cueresponding behaviors during pharmacy counseling sessions with patients with asthma about inhaled corticosteroids: Potential relations with medication beliefs and self-reported adherence. Health Communication: 2016, 31(10), 1266-1275

patient. Thus, refill adherence can only give insight into longer term adherence, which was not the aim of this study.

\section{CONCLUSION}

Patients with asthma expressed few emotional and informational cues during counseling sessions at the pharmacy about ICS.

Many emotional cues were missed. Certain responses, namely, the absence of the provision of inappropriate information and the exploration of informational cues, seem to be clinically relevant. No differences were found between pharmacists' and pharmacy technicians' sessions in cue-responding.

\section{Practice implications}

In encounters with patients, pharmacists and pharmacy technicians need to pay more attention to detecting patients' emotional and informational cues and handle them adequately.

Communication trainings could be useful in improving these skills (Zimmermann et al., 2007). Pharmacists and pharmacy technicians have to avoid providing inappropriate, incomplete, and ambiguous information to patients. Finally, patients have to be encouraged to voice their concerns and informational needs, and need to know that they do not have to be reserved in doing this.

\section{ACKNOWLEDGMENTS}

Data were collected with the help of the Utrecht University pharmacy practice research network (UPPER), and the work was conducted in compliance with the requirements of the UPPER institutional review board of the Department of Pharmacoepidemiology and Pharmacotherapy (http:// www.uu.nl/vkc/upper). We thank the Royal Dutch Association for the Advancement of Pharmacy (KNMP) for sponsoring this study. We also thank Peter Spreeuwenberg for his statistical advice, and patients, pharmacists, and pharmacy technicians for their participation.

\section{REFERENCES}

Al-Jahdali, H. H., Al-Zahrani, A. I., Al-Otaibi, S. T., Hassan, I. S., Al- Moamary, M. S., AlDuhaim, A. S., \& Al-Dawood, A. S. (2007). Perception of the role of inhaled corticosteroids and factors affecting compliance among asthmatic adult patients. Saudi Medical Journal, 28, 569-573.

Baan, D., \& Heijmans, M. J. W. M. (2011). Zelfmanagement vanuit het perspectief van mensen met astma of COPD [Self-management from the perspective of persons with asthma or COPD]. Utrecht, The Netherlands: NIVEL.

Bensing, J. M., \& Dronkers, J. (1992). Instrumental and affective aspects of physician behavior. Medical Care, 30, 283-298. doi:10.1097/ 00005650-199204000-00001 Bensing, J. M., \& Verhaak, P. F. M. (2004). Communication in medical encounters. In A. Kaptein \& J. Weinman (Eds.), Health psychology (pp. 261-287). Oxford, England: Blackwell.

Bertakis, K. D., Roter, D., \& Putnam, S. M. (1991). The relationship of physician medical interview style to patient satisfaction. Journal of Family Practice, 32, 175-181.

Blom, L., \& Krass, I. (2011). Introduction: The role of pharmacy in patient education and counseling. Patient Education and Counseling, 83, 285-287. doi:10.1016/j.pec.2011.05.021 Boulet, L.-P. (1998). Perception of the role and potential side effects of inhaled corticosteroids among asthmatic patients. Chest, 113, 587- 592. doi:10.1378/chest.113.3.587 
Driesenaar, J.A., Smet, P.A.G.M. de, Hulten, R. van, Noordman, J., Dulmen, A.M. van. Cueresponding behaviors during pharmacy counseling sessions with patients with asthma about inhaled corticosteroids: Potential relations with medication beliefs and self-reported adherence. Health Communication: 2016, 31(10), 1266-1275

Bruton, A., Conway, J. H., \& Holgate, S. T. (2000). Reliability: What is it and how is it measured? Physiotherapy, 86(2), 94-99. doi:10.1016/ S0031-9406(05)61211-4

Butow, P. N., Brown, R. F., Cogar, S., Tattersall, M. H., \& Dunn, S. M. (2002). Oncologistív Ve reactions to cancer patients' verbal cues. Psycho- Oncology, 11, 47-58. doi:10.1002/(ISSN)1099-1611

Choi, T. N., Westermann, H., Sayles, W., Mancuso, C. A., \& Charlson, M. E. (2008). Beliefs about asthma medications: Patients perceive both benefits and drawbacks. Journal of Asthma, 45, 409-414. doi:10.1080/ 02770900801971834

Chong, W. W., Aslani, P., \& Chen, T. F. (2013). Pharmacist-patient communication on use of antidepressants: A simulated patient study in community pharmacy. Research in Social \& Administrative Pharmacy. doi:S1551-7411(13)000934[pii];10.1016/j.sapharm.2013.05.006[doi]

Del Piccolo, L., Finset, A., \& Zimmermann, C. (2009). Verona coding definitions of emotional sequences (VR-CoDES) cue and concerns manual 2009. Retrieved from http://www.each.eu/sites/default/ files/VR-Codes-Cue-condern-CoDES-and-unit-ofanalysis-manual.pdf

Driesenaar, J. A., De Smet, P. A. G. M., Van Hulten, R., Hu, L., \& Van Dulmen, S. (2016). Communication during counseling sessions about inhaled corticosteroids at the community pharmacy. Journal of Health Communication. Manuscript submitted for publication.

Engel, G. L. (1977). The need for a new medical model: A challenge for biomedicine. Science, 196(4286), 129-136. doi:10.1126/science.847460

Epstein, R. M., Franks, P., Fiscella, K., Shields, C. G., Meldrum, S. C., Kravitz, R. L., \& Duberstein, P. R. (2005). Measuring patient-centered communication in patient-physician consultations: Theoretical and practical issues. Social Science \& Medicine, 61, 1516-1528. doi:10.1016/j.socscimed.2005.02.001 Global Initiative for Asthma. (2013). From the global strategy for asthma management and prevention. Retrieved from http://www.ginasthma.org

Greenhill, N., Anderson, C., Avery, A., \& Pilnick, A. (2011). Analysis of pharmacist-patient communication using the Calgary-Cambridge guide. Patient Education and Counseling, 83, 423-431. doi:10.1016/j.pec.2011.04.036

Heaven, C., Clegg, J., \& Maguire, P. (2006). Transfer of communication skills training from workshop to workplace:. The Impact of Clinical Supervision. Patient Education and Counseling, 60, 313-325. doi:10.1016/j.pec.2005.08.008

Heaven, C., \& Green, C. (2001). Medical interview aural rating scale. Manchester, UK: Christie Hospital: Psychological Medicine Group.

Horne, R. (2006). Compliance, adherence, and concordance: Implications for asthma treatment. Chest, 130(1), 65S-72S. doi:10.1378/chest.130.1_suppl.65S

Horne, R., \& Weinman, J. (1999a). Patients' beliefs about prescribed medicines and their role in adherence to treatment in chronic physical illness. Journal of Psychosomatic Research, 47, 555-567. doi:10.1016/ S0022-3999(99)00057-4

Horne, R., \& Weinman, J. (1999b). Self-regulation and self-management in asthma: Exploring the role of illness perceptions and treatment beliefs in explaining non-adherence to preventer medication. Psychology \& Health, 14, 1-24. doi:10.1080/08870449908407311

Horne, R., Weinman, J., \& Hankins, M. (1999). The beliefs about medicines questionnaire: The development and evaluation of a new method for assessing the cognitive representation of medication. Psychology \& Health, 14, 1-24. doi:10.1080/08870449908407311

Jansen, J., van Weert, J. C., de Groot, J., van Dulmen, S., Heeren, T. J., \& Bensing, J. M. (2010). Emotional and informational patient cues: The impact of nurses' responses on recall. Patient Education and Counseling, 79, 218-224. doi:10.1016/j.pec.2009.10.010

Juniper, E. F., O'Byrne, P. M., Guyatt, G. H., Ferrie, P. J., \& King, D. R. (1999). Development and validation of a questionnaire to measure asthma control. European Respiratory Journal, 14, 902-907. doi:10.1034/j.1399-3003.1999.14d29.x

Law, A. V., Ray, M. D., Knapp, K. K., \& Balesh, J. K. (2003). Unmet needs in the medication use process: Perceptions of physicians, pharmacists, and patients. Journal of the American Pharmacists Association, 43, 394-402. doi:10.1331/154434503321831111

Mead, N., \& Bower, P. (2002). Patient-centred consultations and outcomes in primary care: A review of the literature. Patient Education and Counseling, 48, 51-61. doi:10.1016/S0738-3991(02)00099-X 
Driesenaar, J.A., Smet, P.A.G.M. de, Hulten, R. van, Noordman, J., Dulmen, A.M. van. Cueresponding behaviors during pharmacy counseling sessions with patients with asthma about inhaled corticosteroids: Potential relations with medication beliefs and self-reported adherence. Health Communication: 2016, 31(10), 1266-1275

Michie, S., Miles, J., \& Weinman, J. (2003). Patient-centredness in chronic illness: What is it and does it matter? Patient Education and Counseling, 51, 197-206. doi:10.1016/S07383991(02)00194-5

Morisky, D. E., Green, L. W., \& Levine, D. M. (1986). Concurrent and predictive validity of a self-reported measure of medication adherence. Medical Care, 24, 67-74. doi:10.1097/00005650-198601000-00007

Murad, M. S., Chatterley, T., \& Guirguis, L. M. (2013). A meta-narrative review of recorded patient-pharmacist interactions: Exploring biomedical or patient-centered communication? Research in Social \& Administrative Pharmacy. doi:S1551-7411(13)000478[pii];10.1016/j.sapharm.2013.03.002[doi]

Murphy, A. C., Proeschal, A., Brightling, C. E., Wardlaw, A. J., Pavord, I., Bradding, P., \& Green, R. H. (2012). The relationship between clinical outcomes and medication adherence in difficult-to-control asthma. Thorax, 67, 751-753. doi:10.1136/thoraxjnl-2011201096

Noldus, L., Trienes, R., Hendriksen, A., Jansen, H., \& Jansen, R. (2000).

The Observer Video-Pro: New software for the collection, management, and presentation of time-structured data from videotapes and digital media files. Behavior Research Methods, Instruments, \& Computers, 32, 197-206. doi:10.3758/BF03200802

Noordman, J., \& van Dulmen, S. (2013). Shared medical appointments marginally enhance interaction between patients: An observational study on children and adolescents with type 1 diabetes. Patient Education and Counseling, 92, 418-425. doi:10.1016/j.pec.2013.06.008

Riley, R.,Weiss, M. C., Platt, J., Taylor, G., Horrocks, S., \& Taylor, A. (2013). A comparison of GP, pharmacist and nurse prescriber responses to patients' emotional cues and concerns in primary care consultations. Patient Education and Counseling, 91, 65-71. doi:10.1016/j.pec.2012.11.009

Sabate, E. (2003). Adherence to long-term therapies: Evidence for action. Geneva, Switzerland: World Health Organization.

Sastre, J., Olaguibel, J., Vega, J. M., Del, P. V., Picado, C., \& Lopez, V. A. (2010). Cut-off points for defining asthma control in three versions of the Asthma Control Questionnaire. Journal of Asthma, 47, 865-870. doi:10.3109/02770903.2010.491149

Uitterhoeve, R., Bensing, J., Dilven, E., Donders, R., deMulder, P., \& van Achterberg, T. (2009). Nurse-patient communication in cancer care: Does responding to patient's cues predict patient satisfaction with communication. Psycho-Oncology, 18, 1060-1068. doi:10.1002/ pon.1434

Uitterhoeve, R., De, L. J., Bensing, J., Heaven, C., Borm, G., Demulder, P., \& van, A. T. (2008). Cue-responding behaviours of oncology nurses in video-simulated interviews. Journal of Advanced Nursing, 61, 71-80.

Unni, E., \& Farris, K. B. (2011). Determinants of different types of medication non-adherence in cholesterol lowering and asthma maintenance medications: A theoretical approach. Patient Education and Counseling, 83, 382-390. doi:10.1016/j.pec.2011.02.017

Van Mil, J. F. (2005). Pharmaceutical care in community pharmacy: Practice and research in the Netherlands. Annals of Pharmacotherapy, 39, 1720-1725. doi:10.1345/aph.1G141

World Health Organization. (2007). Global surveillance, prevention and control of chronic respiratory diseases: A comprehensive approach. Geneva, Switzerland: WHO.

Worley, M. M., Schommer, J. C., Brown, L. M., Hadsall, R. S., Ranelli, P.L., Stratton, T. P., \& Uden, D. L. (2007). Pharmacists' and patients' roles in the pharmacist-patient relationship: Are pharmacists and patients reading from the same relationship script? Research in Social \& Administrative Pharmacy, 3, 47-69. doi:10.1016/j.sapharm.2006.03.003

Zimmermann, C., Del Piccolo, L., \& Finset, A. (2007). Cues and concerns by patients in medical consultations: A literature review. Psychological Bulletin, 133, 438-463. doi:10.1037/0033-2909.133.3.438 
Driesenaar, J.A., Smet, P.A.G.M. de, Hulten, R. van, Noordman, J., Dulmen, A.M. van. Cueresponding behaviors during pharmacy counseling sessions with patients with asthma about inhaled corticosteroids: Potential relations with medication beliefs and self-reported adherence. Health Communication: 2016, 31(10), 1266-1275

\section{TABLES}

Table 1. Examples of patients' cues and pharmacists' and pharmacy technicians' responses.

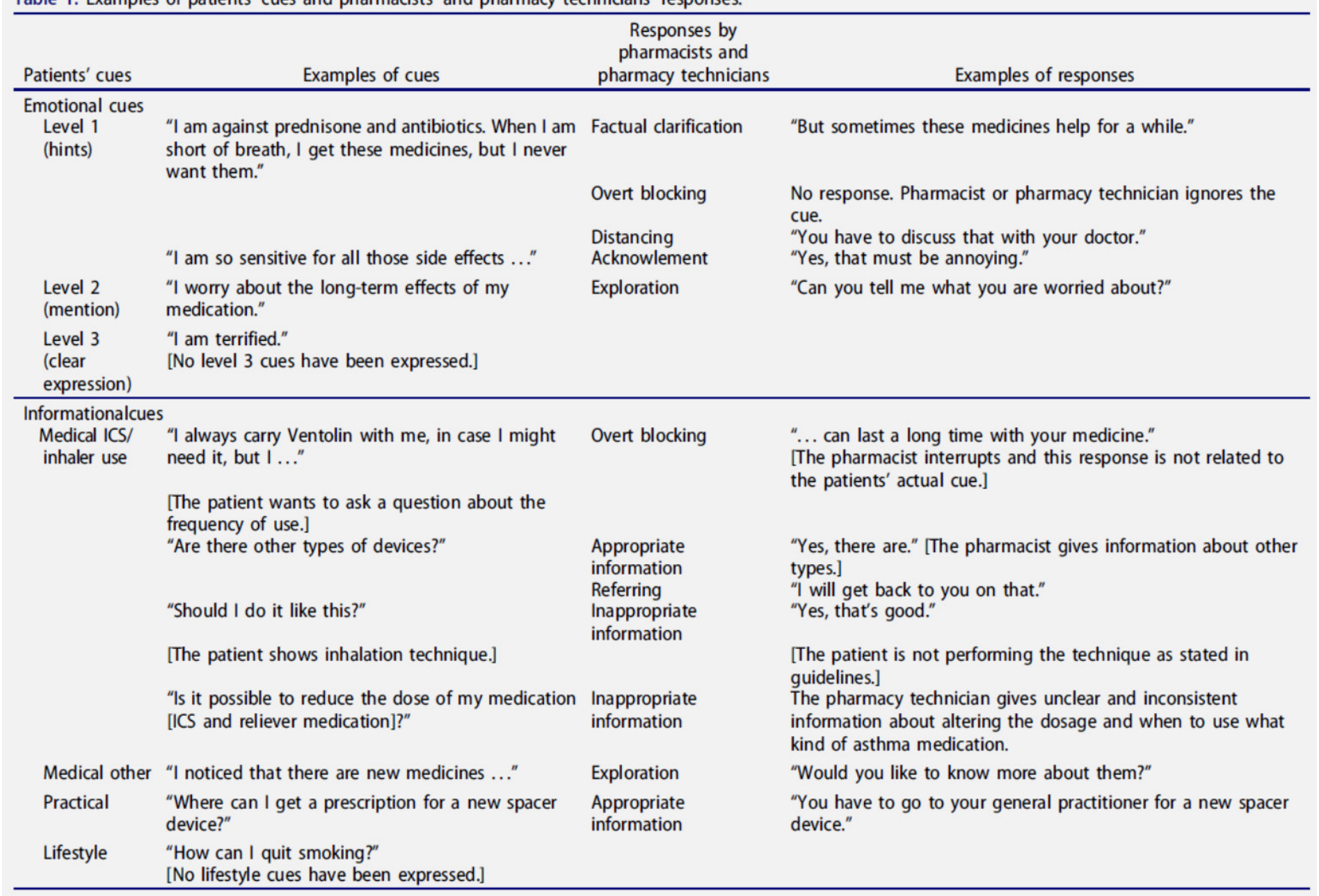


Driesenaar, J.A., Smet, P.A.G.M. de, Hulten, R. van, Noordman, J., Dulmen, A.M. van. Cueresponding behaviors during pharmacy counseling sessions with patients with asthma about inhaled corticosteroids: Potential relations with medication beliefs and self-reported adherence. Health Communication: 2016, 31(10), 1266-1275

Table 2. Patients', pharmacists', and pharmacy technicians' characteristics.

\begin{tabular}{|c|c|c|c|}
\hline Patient characteristics & Pharmacist-patient sessions $(n=44)$ & Technician-patient sessions $(n=42)$ & Total $(n=86)$ \\
\hline Female gender & $29(65.9 \%)$ & $29(69.0 \%)$ & $58(67.4 \%)$ \\
\hline Mean (SD) (range) & $60.2(14.0)(26-82)$ & $56.4(15.8)(28-87)$ & $58.3(15.0)(26-87)$ \\
\hline \multicolumn{4}{|l|}{ Age group, years } \\
\hline $45-64$ & 19 (43.2\%) & 16 (38.1\%) & $35(40.7 \%)$ \\
\hline$>64$ & $19(43.2 \%)$ & $14(33.3 \%)$ & 33 (38.4\%) \\
\hline \multicolumn{4}{|l|}{ Educational level } \\
\hline Low & $8(18.2 \%)$ & $9(21.4 \%)$ & 17 (19.8\%) \\
\hline \multicolumn{4}{|l|}{ Ethnicity $^{\mathrm{a}}$} \\
\hline Dutch & 37 (84.1\%) & 35 (83.3\%) & 72 (83.7\%) \\
\hline Western background & $5(11.4 \%)$ & $5(11.9 \%)$ & $10(11.6 \%)$ \\
\hline Non-Western background & $1(2.3 \%)$ & $2(4.8 \%)$ & $3(3.5 \%)$ \\
\hline \multicolumn{4}{|l|}{ Diagnosis $^{\mathrm{b}}$} \\
\hline Asthma & $31(70.5 \%)$ & $28(66.7 \%)$ & $59(68.6 \%)$ \\
\hline Asthma and COPD & $13(29.5 \%)$ & $14(33.3 \%)$ & 27 (31.4\%) \\
\hline \multicolumn{4}{|l|}{ Duration of ICS use $\mathrm{a}^{\mathrm{a}}$} \\
\hline ACQ score ${ }^{c}$ & $0.9(0.8)$ & $1.0(0.7)$ & $1.0(0.7)$ \\
\hline \multicolumn{4}{|l|}{ Baseline, mean (SD) } \\
\hline \multicolumn{3}{|l|}{ Baseline mean (SD) } & $2.7(1.2)$ \\
\hline $\begin{array}{l}\text { BMQ necessity score } \\
\text { Baseline, mean (SD) }\end{array}$ & $16.2(4.3)$ & $15.8(3.6)$ & $16.0(3.9)$ \\
\hline \multicolumn{4}{|l|}{$\begin{array}{l}\text { BMQ concerns score } \\
\text { Baseline, mean (SD) }\end{array}$} \\
\hline Pharmacist and pharmacy technician characteristics & & \\
\hline \multirow{2}{*}{\multicolumn{4}{|c|}{$\begin{array}{l}\text { Female gender } \\
\text { Age, years }\end{array}$}} \\
\hline & & & \\
\hline Mean $(S D)$ & $36.7(11.5)$ & $35.4(11.9)$ & \\
\hline
\end{tabular}

${ }^{\mathrm{a}}$ One missing in the group of technician-patient sessions.

bBased on self-reports.

'Eleven missings: five missing in the group of pharmacists and six missing in the group of technician-patient sessions. 
Driesenaar, J.A., Smet, P.A.G.M. de, Hulten, R. van, Noordman, J., Dulmen, A.M. van. Cueresponding behaviors during pharmacy counseling sessions with patients with asthma about inhaled corticosteroids: Potential relations with medication beliefs and self-reported adherence. Health Communication: 2016, 31(10), 1266-1275

Table 3. Frequencies of patients' cues and pharmacists' and pharmacy technicians' responses.

\begin{tabular}{|c|c|c|c|}
\hline \multirow[b]{2}{*}{ Elements of the (adapted) MIARS } & \multicolumn{3}{|c|}{ Frequencies $\mathrm{n}(\%)$} \\
\hline & Pharmacists & Pharmacy technicians & Total \\
\hline Patient cues & $113(100 \%)$ & $89(100 \%)$ & $202(100 \%)$ \\
\hline Emotional cues & $34(30.1 \%)$ & $25(28.1 \%)$ & $59(29.2 \%)$ \\
\hline Level 1 (hints) ${ }^{\mathrm{a}}$ & $31(91.2 \%)$ & $24(96.0 \%)$ & $55(93.2 \%)$ \\
\hline Level 2 (mention) & $3(8.8 \%)$ & $1(4.0 \%)$ & $4(6.8 \%)$ \\
\hline Level 3 (clear expression) & - & - & - \\
\hline Informational cues & $79(69.9 \%)$ & $64(71.9 \%)$ & $143(70.8 \%)$ \\
\hline Medical ICS/inhaler use $\mathrm{a}^{\mathrm{a}}$ & $49(62.0 \%)$ & $44(68.8 \%)$ & $93(65.0 \%)$ \\
\hline Medical other ${ }^{\mathrm{a}}$ & $18(22.8 \%)$ & $10(15.6 \%)$ & $28(19.6 \%)$ \\
\hline Practical $^{\mathrm{a}}$ & $12(15.2 \%)$ & $10(15.6 \%)$ & $22(15.4 \%)$ \\
\hline Lifestyle & - & - & - \\
\hline Responses by pharmacists and pharmacy technicians & $113(100 \%)$ & $89(100 \%)$ & $202(100)$ \\
\hline On emotional cues & $34(30.1 \%)$ & $25(28.1 \%)$ & $59(29.2 \%)$ \\
\hline Exploration & $2(5.9 \%)$ & $1(4.0 \%)$ & $3(5.1 \%)$ \\
\hline Acknowledgment $^{\mathrm{a}}$ & $11(32.4 \%)$ & $10(40.0 \%)$ & $21(35.6 \%)$ \\
\hline Factual clarification $^{\mathrm{a}}$ & $16(47.1 \%)$ & $13(52.0 \%)$ & $29(49.2 \%)$ \\
\hline Distancing & $3(8.8 \%)$ & - & $3(5.1 \%)$ \\
\hline Overt blocking & $2(5.9 \%)$ & $1(4.0 \%)$ & $3(5.1 \%)$ \\
\hline On informational cues & $79(69.9 \%)$ & $64(71.9 \%)$ & $143(70.8 \%)$ \\
\hline Exploration $^{\mathrm{a}}$ & $10(12.7 \%)$ & $8(12.5 \%)$ & $18(12.6 \%)$ \\
\hline Appropriate information ${ }^{a}$ & $53(67.1 \%)$ & $38(59.4 \%)$ & $91(63.6 \%)$ \\
\hline Inappropriate information ${ }^{a}$ & $12(15.2 \%)$ & $17(26.6 \%)$ & $29(20.3 \%)$ \\
\hline Distancing & - & $1(1.6 \%)$ & $1(0.7 \%)$ \\
\hline Overt blocking & $2(2.5 \%)$ & - & $2(1.4 \%)$ \\
\hline Referring & $2(2.5 \%)$ & 一 & $2(1.4 \%)$ \\
\hline
\end{tabular}

Note. Results are based on 63 counseling sessions (patients expressed no cues in 23 sessions).

${ }^{\mathrm{a}} \mathrm{Cue} /$ response that occurred in at least 10 sessions and is added to the regression analysis.

Table 4. Emotional and informational communication sequences.

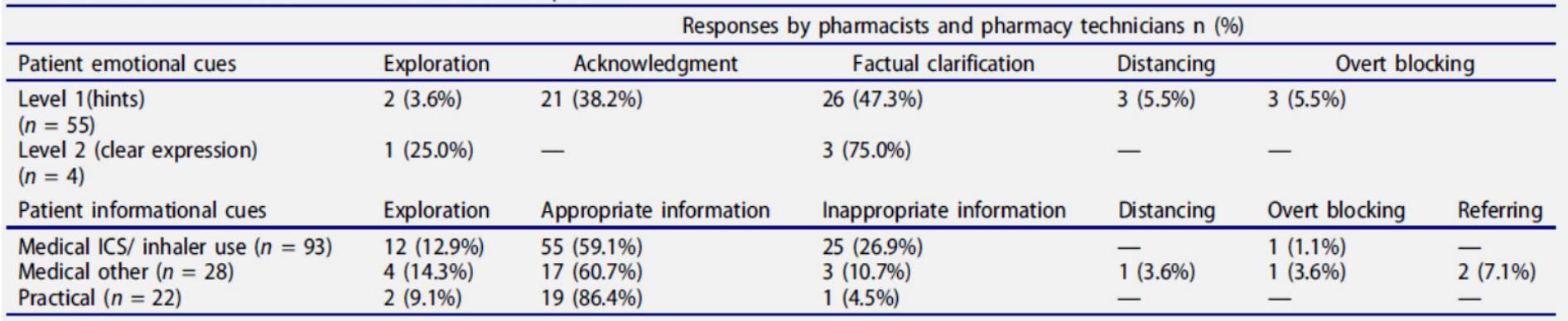

Note. Results are based on 63 counseling sessions (patients expressed no cues in 23 sessions). 
Driesenaar, J.A., Smet, P.A.G.M. de, Hulten, R. van, Noordman, J., Dulmen, A.M. van. Cueresponding behaviors during pharmacy counseling sessions with patients with asthma about inhaled corticosteroids: Potential relations with medication beliefs and self-reported adherence. Health Communication: 2016, 31(10), 1266-1275

Table 5. Multilevel linear regressions of cues and responses on difference scores of beliefs (i.e., concerns and necessities) and self-reported adherence at follow-up measurements.

\begin{tabular}{|c|c|c|c|c|c|}
\hline & \multicolumn{2}{|c|}{ After session } & \multicolumn{3}{|c|}{ Three months after baseline } \\
\hline & $\begin{array}{c}\text { Concerns }^{\mathrm{a}} \\
\text { B (SE) }\end{array}$ & $\begin{array}{c}\text { Necessities }^{\mathrm{a}} \\
\text { B (SE) }\end{array}$ & $\begin{array}{l}\text { Concerns }^{b} \\
\text { B (SE) }\end{array}$ & $\begin{array}{c}\text { Necessities }^{\mathrm{b}} \\
\text { B (SE) }\end{array}$ & $\begin{array}{c}\text { Self-reported adherence } \\
\text { B (SE) }\end{array}$ \\
\hline \multicolumn{6}{|l|}{ Cues } \\
\hline \multicolumn{6}{|l|}{ Emotional cues } \\
\hline Level 1 (hints) $^{\dagger}$ & $0.52(0.68)$ & $-0.55(0.74)$ & $-1.07(0.67)$ & $-0.44(0.72)$ & $-0.10(0.21)$ \\
\hline \multicolumn{6}{|l|}{ Informational cues } \\
\hline Medical ICS/inhaler use ${ }^{\dagger}$ & $0.51(0.66)$ & $0.24(0.73)$ & $-0.46(0.68)$ & $0.67(0.71)$ & $0.32(0.20)$ \\
\hline Medical other ${ }^{\dagger}$ & $-1.19(0.77)$ & $0.25(0.85)$ & $0.07(0.79)$ & $-0.19(0.83)$ & $-0.01(0.23)$ \\
\hline Practical $^{\dagger}$ & $-0.78(0.83)$ & $0.12(0.91)$ & $-0.14(0.84)$ & $-0.86(0.89)$ & $-0.13(0.25)$ \\
\hline \multicolumn{6}{|l|}{ Responses } \\
\hline \multicolumn{6}{|l|}{ On emotional cues } \\
\hline Acknowledgment $^{\dagger}$ & $1.18(0.92)$ & $1.06(0.99)$ & $-0.45(0.91)$ & $0.63(0.95)$ & $-0.07(0.28)$ \\
\hline Factual clarification $^{\dagger}$ & $-0.27(0.83)$ & $-1.43(0.90)$ & $-0.60(0.82)$ & $-1.50(0.86)^{1}$ & $0.13(0.25)$ \\
\hline \multicolumn{6}{|l|}{ On informational cues } \\
\hline Exploration $^{\dagger}$ & $-0.25(0.87)$ & $-0.18(0.95)$ & $0.50(0.87)$ & $0.90(0.91)$ & $0.55(0.25)^{2}$ \\
\hline Appropriate information ${ }^{\dagger}$ & $-0.53(0.67)$ & $0.73(0.73)$ & $-0.10(0.69)$ & $-0.32(0.73)$ & $0.12(0.20)$ \\
\hline Inappropriate information ${ }^{\dagger}$ & $1.57(0.80)^{3}$ & $-1.27(0.87)$ & $0.29(0.81)$ & $-0.87(0.84)$ & $-0.45(0.23)^{4}$ \\
\hline
\end{tabular}

${ }^{\dagger}$ Categorical, dichotomized variable; reference category: no cue/response.

$n=85,1$ missing.

${ }^{b} n=79,7$ missing.

${ }^{1} p=.08$.

${ }^{2} p=.03$.

${ }^{3} p=.049$

${ }^{4} p=.05$.

Note. Bold numbers indicate a significant $\mathrm{p}$-value $(\mathrm{p}<.05)$. 